\title{
Evolution of the seasonal temperature cycle in a transient Holocene simulation: orbital forcing and sea-ice
}

\author{
N. Fischer ${ }^{1,2}$ and J. H. Jungclaus ${ }^{1}$ \\ ${ }^{1}$ Max Planck Institute for Meteorology, Hamburg, Germany \\ ${ }^{2}$ International Max Planck Research School for Earth System Modelling, Hamburg, Germany \\ Received: 19 January 2011 - Published in Clim. Past Discuss.: 3 February 2011 \\ Revised: 14 September 2011 - Accepted: 28 September 2011 - Published: 8 November 2011
}

\begin{abstract}
Changes in the Earth's orbit lead to changes in the seasonal and meridional distribution of insolation. We quantify the influence of orbitally induced changes on the seasonal temperature cycle in a transient simulation of the last 6000 years - from the mid-Holocene to today - using a coupled atmosphere-ocean general circulation model (ECHAM5/MPI-OM) including a land surface model (JSBACH).

The seasonal temperature cycle responds directly to the insolation changes almost everywhere. In the Northern Hemisphere, its amplitude decreases according to an increase in winter insolation and a decrease in summer insolation. In the Southern Hemisphere, the opposite is true.

Over the Arctic Ocean, decreasing summer insolation leads to an increase in sea-ice cover. The insulating effect of sea ice between the ocean and the atmosphere leads to decreasing heat flux and favors more "continental" conditions over the Arctic Ocean in winter, resulting in strongly decreasing temperatures. Consequently, there are two competing effects: the direct response to insolation changes and a sea-ice insulation effect. The sea-ice insulation effect is stronger, and thus an increase in the amplitude of the seasonal temperature cycle over the Arctic Ocean occurs. This increase is strongest over the Barents Shelf and influences the temperature response over northern Europe.

We compare our modeled seasonal temperatures over Europe to paleo reconstructions. We find better agreements in winter temperatures than in summer temperatures and better
\end{abstract}

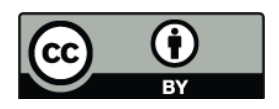

Correspondence to: N. Fischer (nils.fischer@zmaw.de) agreements in northern Europe than in southern Europe, since the model does not reproduce the southern European Holocene summer cooling inferred from the paleo reconstructions. The temperature reconstructions for northern $\mathrm{Eu}-$ rope support the notion of the influence of the sea-ice insulation effect on the evolution of the seasonal temperature cycle.

\section{Introduction}

The amplitude of the seasonal temperature cycle depends on changes in the Earth's orbital parameters that alter the seasonal and the meridional distribution of insolation (Milankovic, 1941; Berger, 1978). The orbital forcing constitutes the dominant natural long-term climate forcing in the last $6000 \mathrm{yr}$, from the mid-Holocene to today (e.g., Wanner et al., 2008; Renssen et al., 2009). The Earth's obliquity was larger $6000 \mathrm{yr}$ ago and, at the same time, summer solstice was closer to perihelion. In the Northern Hemisphere, this resulted in higher insolation in summer and lower insolation in winter, and, consequently, in increased seasonal differences in insolation. So far, it has been assumed that this increase in insolation seasonality has also lead to increased surface temperature seasonality. If this is the case for all latitudes, or if responses of the climate system to insolation changes have to be taken into account is subject of the present study.

The insolation changes act on millennial time-scales and are due to the precession of the Earth's elliptical orbit around the Sun and the changes in obliquity of the Earth's rotation axis with respect to the orbital plane. Annual mean changes in insolation - driven by obliquity changes - were relatively small $\left(<4.5 \mathrm{~W} \mathrm{~m}^{-2}\right.$ at high latitudes) compared to

Published by Copernicus Publications on behalf of the European Geosciences Union. 
the seasonal insolation changes (up to more than $30 \mathrm{~W} \mathrm{~m}^{-2}$ for June insolation at high latitudes). Feedbacks between the different components of the Earth's system, e.g., the sea-icealbedo feedback, have the potential to amplify or dampen the insolation signal. These feedbacks act in different seasons and the annual temperature change is the sum of the seasonal temperature changes that vary in their individual amplitudes. Therefore, the annual signal can be dominated by one particular season, and hence, by seasonality. This leads to changes in climate also on time-scales longer than seasonal as has been shown in several time-slice simulation studies (e.g., Braconnot et al., 2007a; Otto et al., 2009).

Denton et al. (2005) discuss the role of seasonality in abrupt climate change events during the last $60000 \mathrm{yr}$ by means of temperature reconstructions from ice cores and glacier advances in Greenland. The authors find that during abrupt cold climate events, the annual temperature anomalies in high northern latitudes are dominated by the winter temperature anomalies that are caused by increased winter seaice cover in the Northern Hemisphere. This leads to "continental" conditions over large parts of the northern high latitudes and thus to an increase in the amplitude of the seasonal temperature cycle.

Previous large-scale proxy-based studies that analyzed Holocene summer and winter temperatures consist of compilations of local climate reconstructions and are mainly focused on the mid-Holocene ( $6 \mathrm{ka}$ ) because of different dating procedures and different temporal resolutions of the individual reconstructed temperature time-series. Cheddadi et al. (1996) find higher summer and winter temperatures in northern European high latitudes and lower winter and summer temperatures in the Mediterranean region. Similar results for high and lower Northern Hemisphere latitudes are found for Siberia (Tarasov et al., 1999) and in a more recent survey, on high northern latitude temperatures by Sundqvist et al. (2010). There is qualitative agreement between the time-slice studies and the evolution of seasonal temperatures throughout the Holocene over Europe, presented in Davis et al. (2003). The results of this study are compared to our simulation results later in the present study.

Time-slice simulations of the mid-Holocene with coupled AO-GCMs have been part of the PMIP2-initiative (e.g., Braconnot et al., 2007a,b) that covered various aspects of the climate system but did not investigate the response of the seasonal temperature cycle to changes in insolation. The same is true for transient simulations of the Holocene performed with either Earth system models of intermediate complexity (e.g., Renssen et al., 2009) or transient Holocene simulations with AO-GCMs simulations and accelerated orbital forcing (Lorenz et al., 2006).

Transient simulations allow us to check whether the climate model exhibits any non-linear responses to the applied orbital forcing. These responses have been found, e.g., in low latitude vegetation in previous studies on Holocene climate studies (e.g., Claussen et al., 1999; Liu et al., 2006).
A further advantage of transient simulations is the improved comparability of the model results to reconstructions from paleo-climate-proxies. Climate models tend to have biases in certain simulated quantities and also reconstructed data have uncertainties. Transient simulations enable us to compare the trends in the climate variable and therefore allow for a more robust assessment of temporal changes in the climate system.

In this study, we investigate how changes in insolation affect the mean climate evolution and the evolution of the seasonal cycle from the mid-Holocene to today. Given the seasonal distribution of insolation in the Northern Hemisphere in the mid-Holocene, the expected direct respone is a decrease in the amplitude of the seasonal temperature cycle in the course of the last $6000 \mathrm{yr}$. Nevertheless, sea-ice evolution over the Arctic Ocean and the interaction between atmosphere, ocean, and sea ice may alter this direct response. In the first part of this study, we present the evolution of the seasonal temperature cycle over the last $6000 \mathrm{yr}$ in a coupled atmosphere-ocean model with an integrated dynamic land surface model. In the second part, we compare the simulation results to Holocene temperature reconstructions obtained from pollen archives.

\section{Model setup and experimental design}

We perform a 6000-year-long transient simulation with the coupled atmosphere-ocean general circulation model ECHAM5/MPI-OM (Jungclaus et al., 2006), including the land surface model JSBACH (Raddatz et al., 2007) with a dynamic vegetation module (Brovkin et al., 2009) accounting for vegetation induced changes in surface properties. The atmosphere component ECHAM5 (Roeckner et al., 2003) is run in resolution T31 (corresponding to $3.75^{\circ}$ ) and the ocean component MPI-OM (Marsland et al., 2003) is run in resolution GR30 (corresponding to $\sim 3^{\circ}$ ). The ocean model component includes a Hibler-type zero-layer dynamic-thermodynamic sea-ice model with viscous-plastic rheology (Semtner, 1976; Hibler, 1979).

Since we are mainly interested in the effects of orbital forcing on the evolution of the seasonal temperature cycle, we do not apply further external forcing such as solar, volcanic, or greenhouse gases and set greenhouse gas concentrations to pre-industrial values $\left(\mathrm{CO}_{2}\right.$ to $280 \mathrm{ppm}, \mathrm{CH}_{4}$ to $700 \mathrm{ppb}, \mathrm{N}_{2} \mathrm{O}$ to $265 \mathrm{ppb}$ ). Thus, we do not expect the model results to perfectly match climate reconstructions. Rather, we are interested in finding mechanisms that determine the changes in the seasonal temperature cycle from the midHolocene to today. We apply orbital forcing on a yearly basis following (Bretagnon and Francou, 1988) implemented in the radiation scheme of the atmosphere model component, which are similar to other calculations of insolation change (e.g., Berger, 1978). We do not apply any acceleration technique and can thus analyze the ocean's response to changes in insolation on orbital timescales. We initialize the transient 
experiment from a 3500-year-long mid-Holocene $(6000 \mathrm{yr}$ before present) time-slice simulation with orbital forcing presented in an earlier study (Fischer and Jungclaus, 2010).

\section{Results and discussion}

For the following analysis, we use monthly mean output from both the atmosphere and the ocean model with the standard present-day calendar. The time-period of reference is the mid-Holocene, i.e., $6000 \mathrm{yr}$ before present.

\subsection{Seasonal insolation and sea-ice effects}

We define the amplitude of the seasonal temperature cycle (STCA) as the surface temperature difference between the coldest and the warmest month of the year. Similarly, we define the amplitude of the seasonal insolation cycle (SICA) as the difference between annual maximum and minimum incoming short wave radiation on a monthly mean basis. SICA depends on the external orbital forcing only. Fig. 1a and c show zonally averaged Hovmoeller-type diagrams of the evolution of SICA and STCA, respectively, from the midHolocene to today. Changes in STCA follow those in SICA qualitatively with the exception of the high northern latitudes where, despite decreasing SICA, STCA increases.

\subsubsection{Low and mid-latitude response}

In the low- and mid-latitudes of the Northern Hemisphere $(\mathrm{NH})$, the maximal STCA response is shifted northwards from $15^{\circ}$ to $40^{\circ} \mathrm{N}$ for the maximum decrease in STCA and southwards from $15^{\circ}$ to $30^{\circ} \mathrm{S}$ for the low- and mid latitudes increase in STCA in the Southern Hemisphere (SH). The difference between SICA and STCA in low- and mid latitudes can be attributed to planetary albedo effects. Figure $1 \mathrm{~b}$ shows the evolution of the net incoming short wave radiation seasonal cycle amplitude (net SICA) that includes the planetary albedo effect and that corresponds more closely to STCA. The difference between SICA and net SICA in low- and mid latitudes occurs because of a southward shift of the intertropical convergence zone (ITCZ) over Africa (calculated after Braconnot et al., 2007b, not shown) and thus a decrease in cloud cover over the NH low latitudes and an increase in the SH ITCZ region.

Over the NH continents and sub-Arctic oceans, STCA decreases according to the decrease in SICA, with the strongest decrease over North Africa, the northern part of the Arabian Peninsula, and central Asia (Fig. 2). In the SH's low and midlatitudes, STCA increases over the oceans and Australia, but decreases over South America and southern Africa probably due to the southward shift of the ITCZ.

Zonal changes in surface temperature, an increase at low latitudes, and a decrease in high latitudes (Fig. 3) correspond to the changing insolation distribution with increasing insolation around the equator in boreal winter and decreasing in-
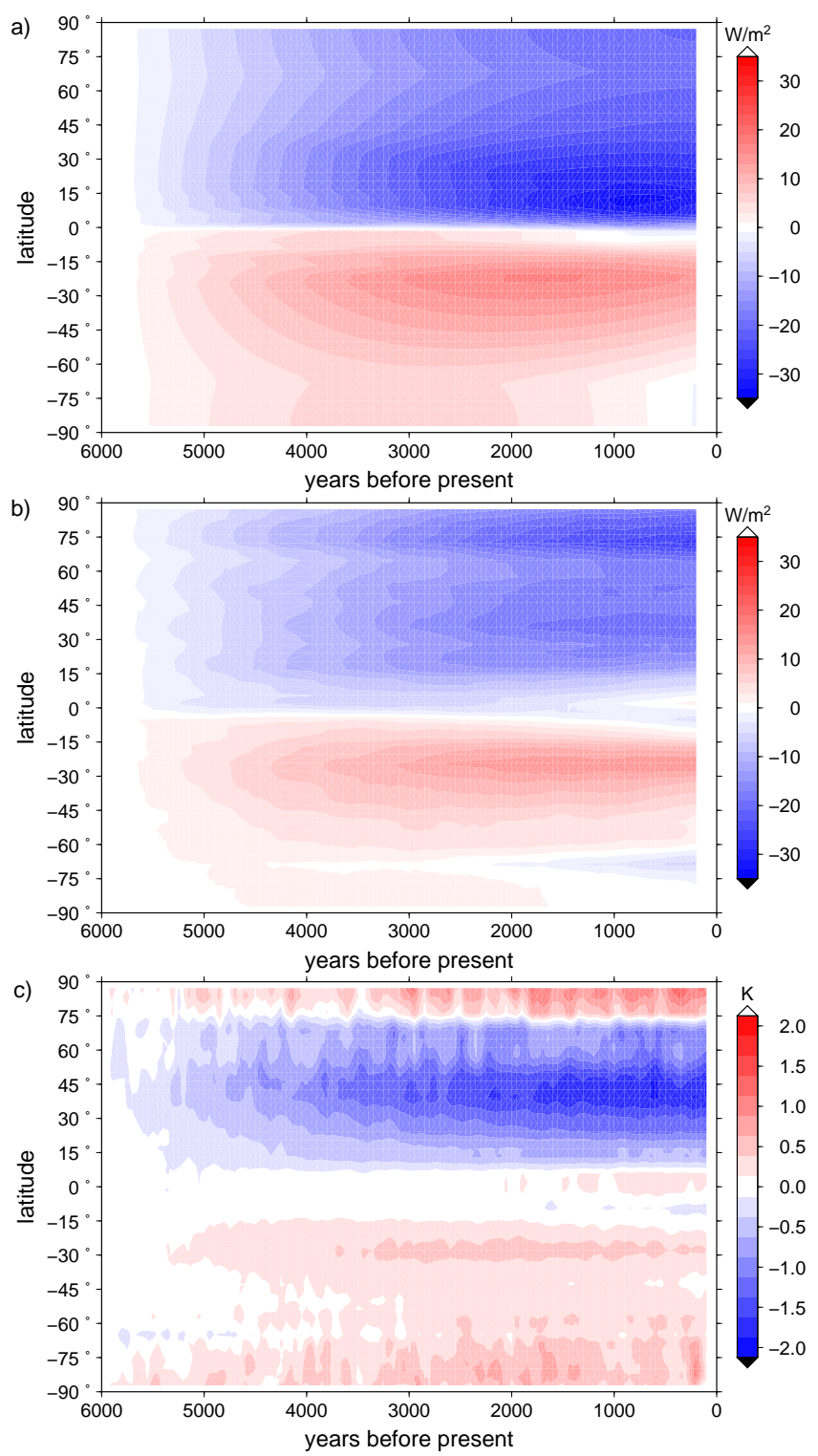

Fig. 1. Zonal mean Hovmoeller type diagrams of (a) seasonal insolation cycle amplitude (difference between yearly maximum and minimum insolation in $\mathrm{W} \mathrm{m}^{-2}$ ), (b) seasonal net insolation cycle amplitude (including planetary albedo), and (c) seasonal temperature cycle amplitude (difference between annual maximum and minimum zonal mean temperature). The panels show anomalies with respect to conditions at the mid-Holocene (mean of the first $100 \mathrm{yr}$ of the simulation).

solation at high northern latitudes in boreal summer (Fig. 4). In the low latitudes, the insolation induced warming in winter is accompanied by a southward migration of the ITCZ, which leads to a strong decrease in cloud cover and precipitation in the monsoon season from late summer to autumn both over the Indian sub-continent and the Sahel region. Due to these two effects, the direct insolation effect in winter and 


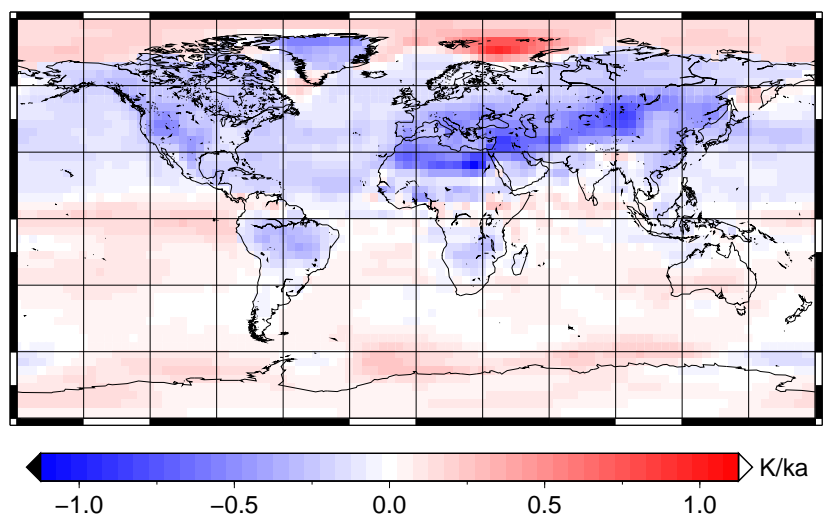

Fig. 2. Linear trend in seasonal cycle amplitude (difference between warmest and coldest month) over the simulation period in $\mathrm{K} \mathrm{ka}^{-1}$ Kelvin per $1000 \mathrm{yr}$.

the decreased cloud cover in summer, the warming signal is present the whole year. The STCA decrease is strongest just north of these warming regions and is dominated by the insolation changes: a decrease in summer insolation and thus temperature, and an increase in both in winter.

\subsubsection{High latitude response}

The increase in STCA at high northern latitudes cannot be explained by net SICA, which decreases at high northern latitudes. The spatially resolved plot of linear trends in STCA (Fig. 2) shows that the increase in STCA at high northern latitudes is confined to the Arctic Ocean, with the strongest signal over the Barents Shelf. This zonal mean increase outweighs the decrease in STCA over the continents at the same latitude bands. The expansion of sea-ice cover in the course of the experiment is the cause for the signal, as we will show in the following.

Decreasing summer insolation in the high northern latitudes reduces summer sea-ice melt and therefore leads to an increase in the September sea-ice extend in the Arctic Ocean from $70 \%$ to $80 \%$ (Fig. 5). In the annual mean, sea-ice cover increases from 90 to $95 \%$. With reduced sea-ice cover under mid-Holocene conditions, the ocean acts as a reservoir, gaining heat in the summer months and releasing it in the winter months, and thus dampening the STCA. Due to the increase in sea-ice cover throughout the simulation, the sea ice acts as an insulator and inhibits the heat reservoir effect. As a consequence, the annual mean atmosphere-ocean heat flux over the Arctic decreases in absolute values by $13 \%$ from -7.4 to $-6.6 \mathrm{~W} \mathrm{~m}^{-2}$ (positive values indicate heat flux directed from the atmosphere to the ocean). The seasonal cycle of heat flux over the Arctic Ocean (Fig. 5) decreases by $22 \%$, with the summer heat flux decreasing from 70 to $52 \mathrm{~W} \mathrm{~m}^{-2}(24 \%)$ and the winter heat flux decreasing in absolute values from -36 to $-28 \mathrm{~W} \mathrm{~m}^{-2}$ (22\%). For comparison, the difference in incoming radiation at the top of the atmosphere in summer

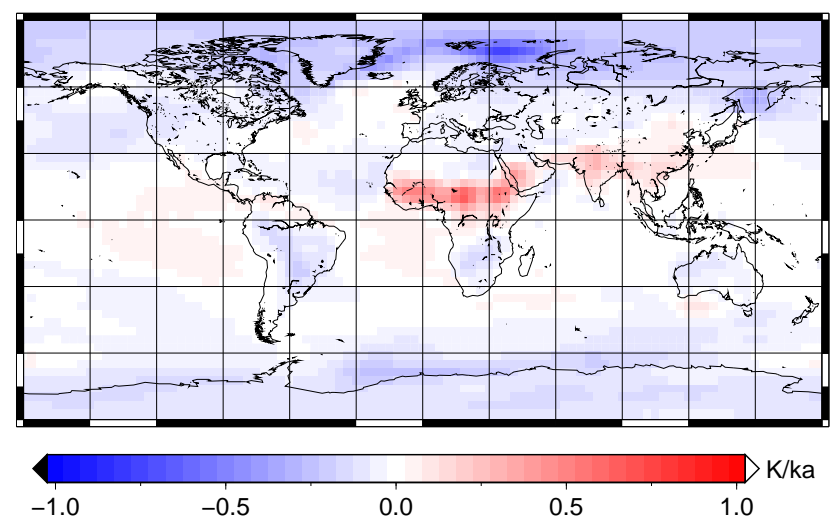

Fig. 3. Linear trend in annual mean surface temperature over the simulation period in $\mathrm{K} \mathrm{ka}^{-1}$ - Kelvin per $1000 \mathrm{yr}$

is $30 \mathrm{~W} \mathrm{~m}^{-2}(6.6 \%)$ and $12.66 \mathrm{~W} \mathrm{~m}^{-2}(16 \%)$ for the net surface shortwave radiation.

The decrease in the amplitude of the seasonal cycle of seaice is due to an increase in summer sea-ice cover and the continental boundaries of the Arctic Ocean basin that limit winter sea-ice extent when the whole basin is sea-ice covered. In the Arctic Ocean, especially over the Barents Shelf and along the east coast of Greenland, cooling is enhanced where sea ice is expanding. The cooling signal is strongest in autumn and in winter, when - compared to the mid-Holocene conditions - sea-ice cover acts as an insulator and heat flux between the ocean and the atmosphere is inhibited. Thus, the autumn and winter temperatures sink, despite the fact that winter insolation is not changing significantly. So the sea-ice insulation effect dominates the STCA. This is similar to the mechanism proposed to explain the abrupt climate changes in the last $60000 \mathrm{yr}$ in Denton et al. (2005). Extensive winter sea-ice cover in the Arctic Ocean leads to "continental" climate conditions over the Arctic region and cooler winters in the late Holocene compared to the mid-Holocene, when reduced sea-ice cover and thus open ocean in the Arctic region acts as a heat reservoir and thus leads to warmer winters.

This affects not only the Arctic Ocean, but also influences the adjacent continents. The sea-ice insulation effect could be amplified by a synergy of the sea-ice albedo effect and the snow-albedo feedback due to the shift of the northern tree-line in the Holocene. The strength of the synergetic effect of the sea-ice albedo and the snow-albedo feedbacks in the model setup used here, however, have been shown to be small (Otto et al., 2009). This might be related to the fact that the soil albedo is static in the current model setup and does not evolve with vegetation changes. Using a different model, Renssen et al. (2005) showed that the vegetation feedback is indeed important for summer temperature changes in the high northern latitudes. The strength of this effect could potentially increase by including a dynamic soil albedo scheme (Vamborg et al., 2011) in the current model. 

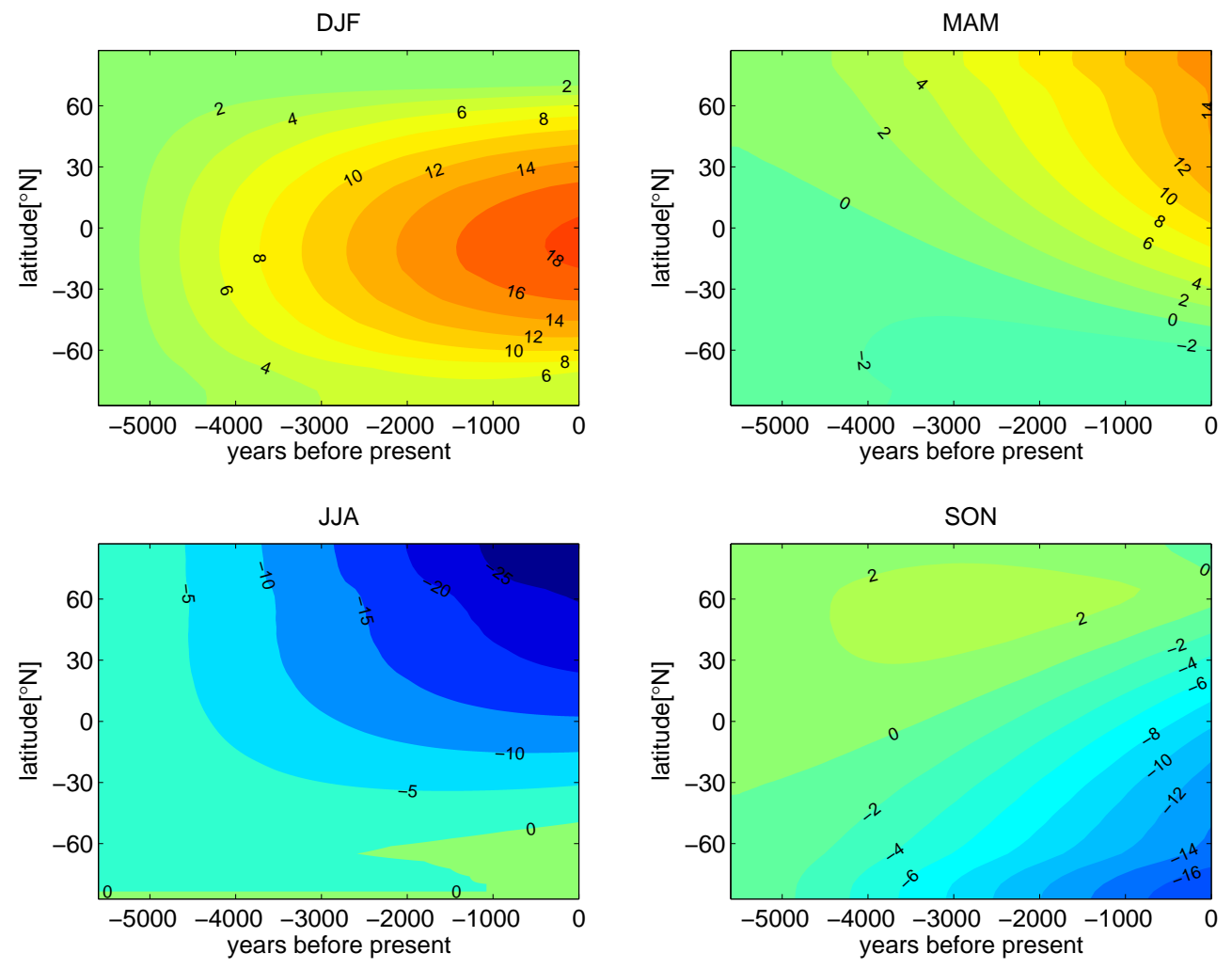

Fig. 4. Changes in seasonal insolation from the mid-Holocene to today in $\mathrm{W} \mathrm{m}^{-2}$ (winter - DJF, spring - MAM, summer - JJA, autumn SON, seasons are defined after present-day's calendar). The reference is $6000 \mathrm{yr}$ before present.

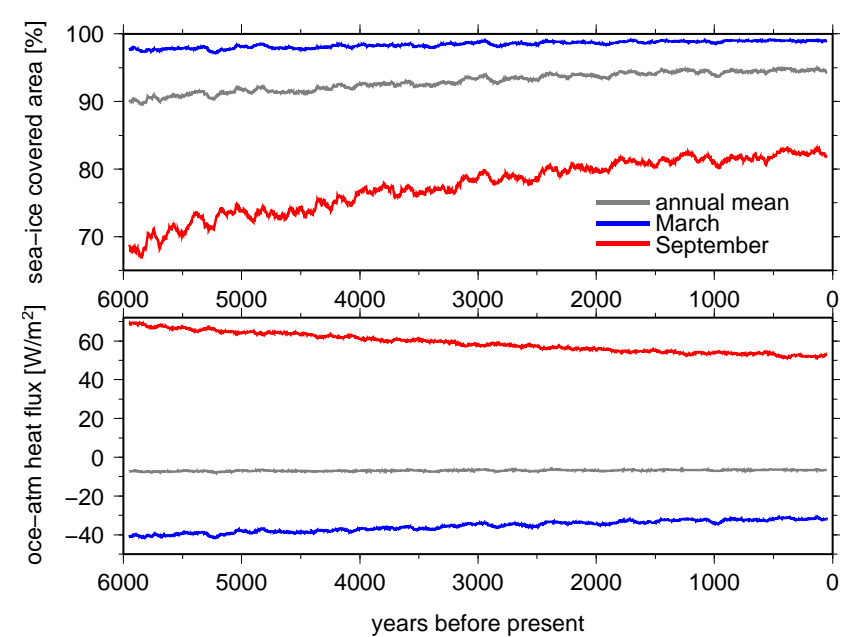

Fig. 5. Upper panel: percentage of sea-ice covered area in the Arctic Ocean, lower panel: atmosphere-ocean heat flux in $\mathrm{W} \mathrm{m}^{-2}-$ positive values from the atmosphere to the ocean. Both panels show 100-year running means.
In the SH high latitudes, both SICA and STCA increase, but the increase in STCA is disproportional to the increase in SICA and net SICA (Fig. 1). The increase in STCA over the Southern Ocean is stronger than the increase over Antarctica (Fig. 2), which suggests that sea-ice might be affecting the STCA response. Austral summer insolation at high southern latitudes increases by only $5 \mathrm{~W} \mathrm{~m}^{-2}$ and insolation changes in austral autumn and winter are less than $2 \mathrm{~W} \mathrm{~m}^{-2}$ (Fig. 4). A strong decrease of $16 \mathrm{~W} \mathrm{~m}^{-2}$ occurs in austral spring, which leads to an increase in maximum sea-ice extent (Please note that the effect may be influenced by the fact that the length of the seasons is changing in the course of the last $6000 \mathrm{yr}$ (Joussaume and Braconnot, 1997)). Nevertheless, decreased insolation in austral spring and the slight increase in summer insolation lead to an increase in the seasonal cycle in sea-ice cover. The mechanisms and dynamics transferring the seasonal insolation changes to a response in sea-ice cover are similar to those described for the Arctic Ocean, but in case of the Southern Ocean, they act in the same direction as the changes in insolation. The increase in the seasonal cycle in sea-ice cover occurs despite the fact that the Southern Ocean's minimal sea-ice extent in the late Holocene is larger than that in the mid-Holocene. The increase in the amplitude of the seasonal sea-ice cycle then amplifies the increase in STCA. 

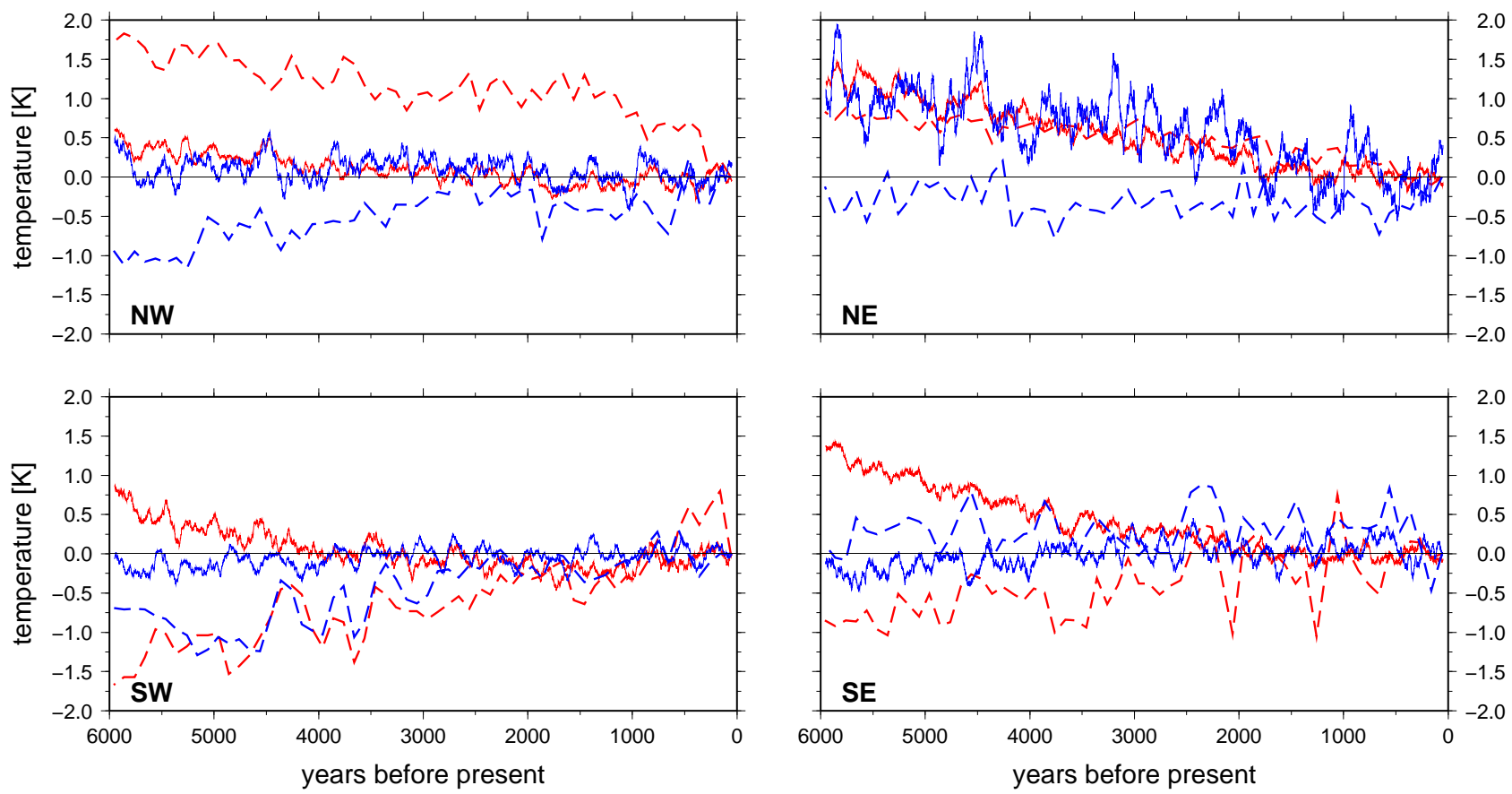

Fig. 6. Comparison of seasonal temperature evolution between model results (solid lines) and reconstructions from pollen data (dashed lines, Davis et al. (2003)) for northwestern (NW), northeastern (NE), southwestern (SW), and southeastern (SE) Europe - summer temperatures (red), winter temperatures (blue). Changes with respect to today's temperatures.

Thus, we find two effects determining STCA in the midand late Holocene: seasonal insolation distribution and seaice cover. In the low- and mid-latitudes, seasonal insolation distribution dominates STCA; in the high latitudes, the insolation signal dampens (in the $\mathrm{NH}$ ) or enhances (in the $\mathrm{SH}$ ) the effect of sea-ice cover on STCA.

\subsection{Comparison with temperature reconstructions for Europe}

We compare the model results with the reconstruction of European winter and summer temperatures inferred from 620 pollen archives by Davis et al. (2003). In their paper, the authors sub-divide the European continent into six zones: northern, central, and southern Europe, with an eastern and western part each. Since the resolution of our model is quite coarse, we discuss only changes for northern and southern Europe and the respective western and eastern parts, with $15^{\circ} \mathrm{E}$ being the boundary between east and west and $50^{\circ} \mathrm{N}$ being the boundary between northern and southern Europe.

The model results agree with the reconstructed data in trend and amplitude in northeastern European summer and southeastern European winter. Qualitatively, the model reproduces the reconstructed temperatures in northeastern $\mathrm{Eu}$ ropean summer and winter temperatures in southern Europe, but with different amplitudes. The most obvious discrepancy appears to be in southern European summer temperatures, where the model results exhibit a decrease and the reconstructed temperatures an increase, but also northern European winter temperatures differ between model and reconstructions.

In a recent study, Davis and Brewer (2009) find the same discrepancies when they compare their reconstructed data to Holocene time-slice model results from the PMIP2-exercise (Braconnot et al., 2007a). Davis and Brewer (2009) attribute the discrepancies to how climate models simulate the response of the latitudinal temperature gradient (LTG) between mid and high northern latitudes to a changing latitudinal insolation gradient (LIG) (Raymo and Nisancioglu, 2003).

Davis and Brewer (2009) define the LIG and the LTG as the difference between the latitude bands $55-75^{\circ} \mathrm{N}$ and 30 $45^{\circ} \mathrm{N}$ in insolation and temperature, respectively, and show that reconstructed Holocene summer and winter LTG follow the respective LIG closely (Fig. 7a). For the modeled seasonal LTGs of the present study, however, this is only true for the winter, whereas the summer LTG is strongly divergent from the summer LIG (Fig. 7b).

Summer LTG calculated from European temperature differences for late spring season (April to June) does resemble the LIG (not shown). But since other independent methods such as pollen-climate reconstruction based on inverse modeling approaches to reconstruct mid-Holocene climate $(\mathrm{Wu}$ et al., 2007) indicate a Holocene summer cooling as well, this temporal shift is a rather improbable solution to the problem.

The modeled summer LTG follows the LIG if all continents are considered (Fig. 7c), although the trend in the 
a)

pollen reconstruction by Davis et al. (2003)
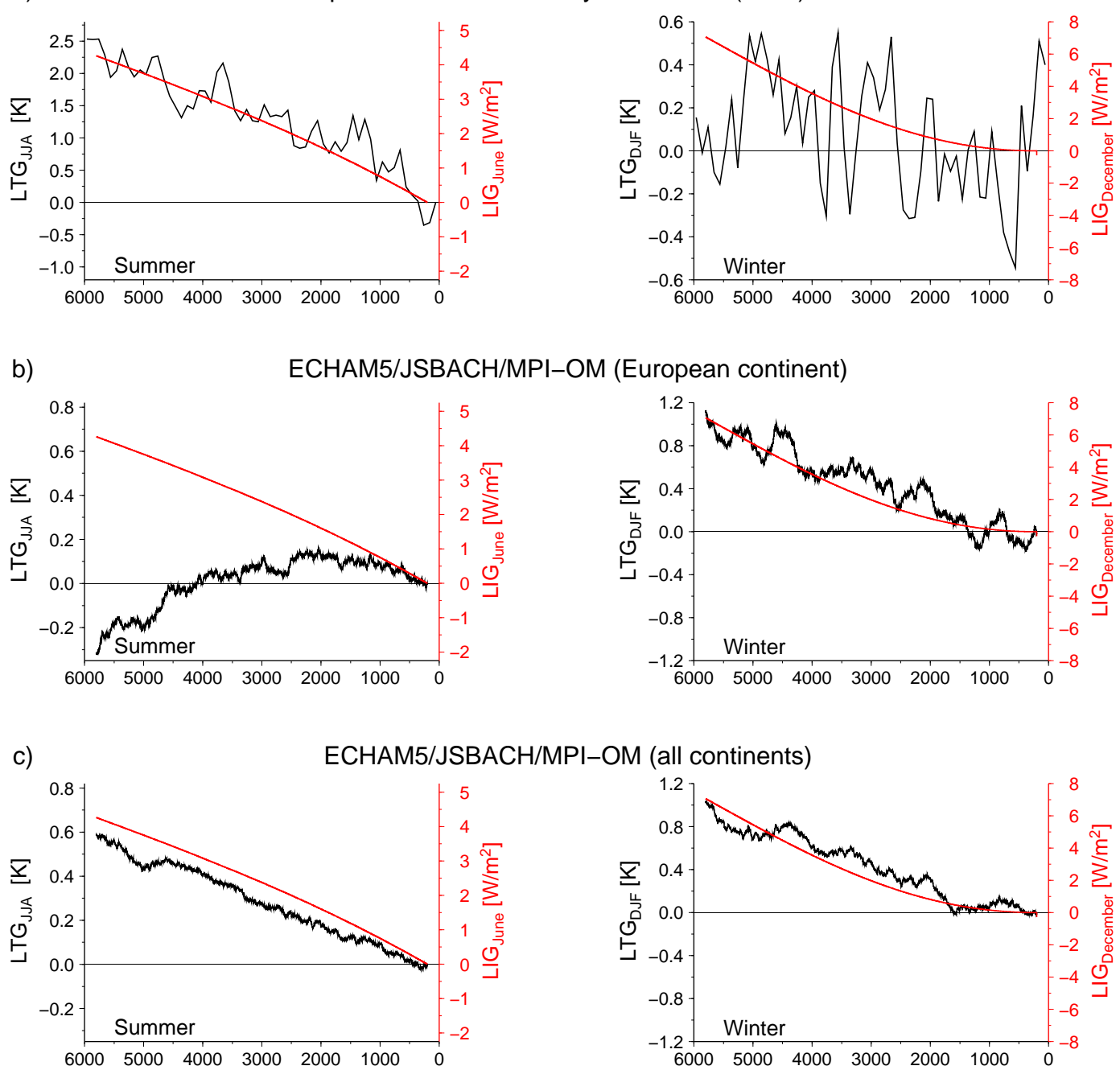

Fig. 7. Seasonal latitudinal temperature gradients (in $\mathrm{K}$, black lines, left $\mathrm{y}$-axes) and June and December insolation gradients (in $\mathrm{W} \mathrm{m}^{-2}$, red lines, right $\mathrm{y}$-axes). Both defined as the difference between the latitude bands $55-75^{\circ} \mathrm{N}$ and $30-45^{\circ} \mathrm{N}$ in temperature and insolation, respectively. (a) Temperature reconstruction from pollen (after Davis and Brewer (2009), subset of their Fig. 7, correlation between winter LIG and LTG is 0.4), (b) corresponding model results for the European continent, and (c) model results for all continental land masses.

summer LTG in the model is weaker than the pollenreconstructed trend in LTG. For the pollen-reconstructed temperatures, the argument of LTG sensitivity to LIG is shown to be valid for all Northern Hemisphere continents as well (Davis et al., 2011). It is possible that the discrepancy between reconstructed and modeled European temperatures is due to the coarse resolution of the model that is not resolving changes in the atmospheric circulation induced by insolation changes correctly. The discrepancy could also result from a feedback or mechanism that is missing in the model. The missing summer cooling signal in southern Europe and the Mediterranean region is not specific for the model setup used in this study, but it is a common feature of coupled climate models (Braconnot et al., 2007b), in all of which midHolocene cooling is confined to the monsoon regions. This low latitude summer cooling is related to the strength of the reconstructed summer LTG trend and can explain the difference in amplitude compared to the modeled summer LTG strength.

Nevertheless, because of the correspondence on the hemispheric scale between paleo reconstructions and model data and the qualitatively reasonable agreement between the two in northern latitudes, we argue that the effect of changing insolation and indirect effects, such as sea-ice cover, have to be taken into account when interpreting reconstructed seasonal and also annual mean temperatures.

In addition, despite the discrepancies between the modeled and the reconstructed LTG, the reconstruction also indicates that STCA decreases more strongly in the northwestern part of Europe than in the northeastern part. This supports the 


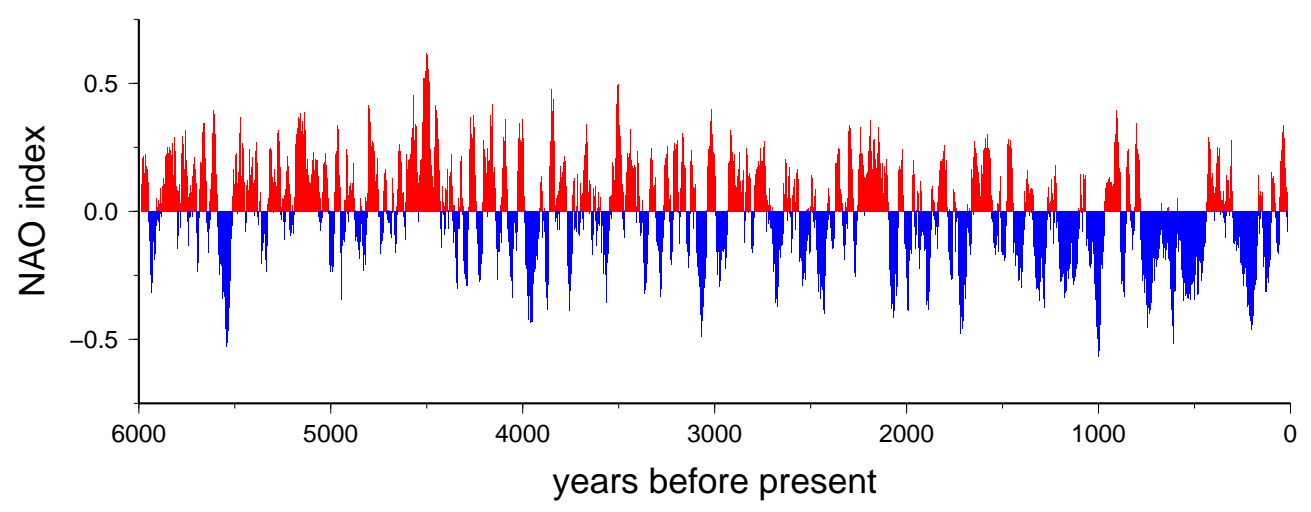

Fig. 8. Time-series of North Atlantic Oscillation index calculated from the first EOF of winter mean sea level pressure over the North Atlantic region (30-year running mean).

notion of the influence of the sea-ice evolution in the Arctic Ocean and especially over the Barents Shelf on STCA. Still, since on these regional scales the model results diverge from the reconstructions, we cannot exclude the possibility that there are other reasons for this behavior in the proxy data that are not captured by the model.

The increase in the simulated southern European and Mediterranean winter temperatures from the mid-Holocene to today, present in the reconstructions and the model, is likely related to a change in the North Alantic Oscillation (NAO, Fig. 8). The NAO-index shows a trend from dominating NAO positive states to prevailing NAO negative states. Under mid-Holocene conditions, the more frequent positive NAO-states lead to a northward shift in the winter storm tracks that yield relatively warm and wet conditions in northern Eurpoe and cool and dry conditions in southern Europe. Climate reconstructions also indicate a more positive NAOindex during the mid-Holocene (Nesje et al., 2001; Davis and Stevenson, 2007). Climate models show an ambiguous response of the NAO under mid-Holocene conditions with a tendency towards more positive NAO phases (Gladstone et al., 2005), which is also the case in the present study. We do not find significant changes in amplitude or frequency in the NAO throughout the simulation.

\section{Conclusions}

We investigated the response of the seasonal temperature cycle amplitude to orbitally induced changes in temporal and meridional insolation distribution. The amplitude of the seasonal temperature cycle in the Holocene is determined by seasonal insolation distribution in the low and mid latitudes and by sea-ice cover and the sea-ice insulation effect in the high latitudes. In the Northern Hemisphere's high latitudes, the sea-ice insulation effect outweighs the insolation effect; in the Southern Hemisphere's high latitudes, the sea-ice insulation effect amplifies the insolation effect. Despite the decrease in the amplitude of the seasonal insolation cycle, the amplitude of the seasonal temperature cycle increases in the Arctic Ocean and diminishes the seasonal temperature cycle amplitude's decrease on the adjacent continents. Annual mean temperature changes in the high northern latitudes are dominated by a decrease in winter temperatures, whereas summer temperatures decrease to a lesser extent. Comparison of the model results to a reconstruction from paleo archives also indicates an influence of sea-ice evolution on the seasonal temperature cycle amplitude. Discrepancies between the reconstruction and the model results are most obvious in the southern European summer, where the model does not reproduce the mid-Holocene cooling inferred from various climate proxies. On the global scale, the modeled response in the latitudinal temperature gradient to the latitudinal insolation gradient matches the reconstructed response, suggesting that the coarse resolution version of the model might be responsible for the mismatch. Nevertheless, within a limited region such as Europe, the low latitude summer cooling inferred from pollen reconstructions is not captured by the model.

Acknowledgements. We are grateful to Martin Claussen and two anonymous referees for their constructive comments and suggestions that helped to improve the manuscript. We would also like to thank Basil Davis for providing the data-set for the Holocene temperature reconstruction in Europe and very helpful comments on an earlier version of the manuscript. This work has been performed within the priority program INTERDYNAMIK of the German Research Foundation (DFG). The model integration was performed on the Linux-cluster of the German Climate Computing Center (DKRZ) in Hamburg.

The service charges for this open access publication have been covered by the Max Planck Society.

Edited by: P. Braconnot 


\section{References}

Berger, A.: Long-Term Variations Of Daily Insolation And Quaternary Climatic Changes, J. Atmos. Sci., 35, 2362-2367, 1978.

Braconnot, P., Otto-Bliesner, B., Harrison, S., Joussaume, S., Peterchmitt, J.-Y., Abe-Ouchi, A., Crucifix, M., Driesschaert, E., Fichefet, Th., Hewitt, C. D., Kageyama, M., Kitoh, A., Lan, A., Loutre, M.-F., Marti, O., Merkel, U., Ramstein, G., Valdes, P., Weber, S. L., Yu, Y., and Zhao, Y.: Results of PMIP2 coupled simulations of the Mid-Holocene and Last Glacial Maximum Part 1: experiments and large-scale features, Clim. Past, 3, 261277, doi:10.5194/cp-3-261-2007, 2007a.

Braconnot, P., Otto-Bliesner, B., Harrison, S., Joussaume, S., Peterchmitt, J.-Y., Abe-Ouchi, A., Crucifix, M., Driesschaert, E., Fichefet, Th., Hewitt, C. D., Kageyama, M., Kitoh, A., Loutre, M.-F., Marti, O., Merkel, U., Ramstein, G., Valdes, P., Weber, L., Yu, Y., and Zhao, Y.: Results of PMIP2 coupled simulations of the Mid-Holocene and Last Glacial Maximum - Part 2: feedbacks with emphasis on the location of the ITCZ and mid- and high latitudes heat budget, Clim. Past, 3, 279-296, doi:10.5194/cp-3-279-2007, 2007b.

Bretagnon, P. and Francou, G.: Planetary theories in rectangular and spherical variables - VSOP 87 solutions, Astron. Astrophys., 202, 309-315, 1988.

Brovkin, V., Raddatz, T., Reick, C. H., Claussen, M., and Gayler, V.: Global biogeophysical interactions between forest and climate, Geophys. Res. Lett., 36, L07405, doi:10.1029/2009GL037543, 2009.

Cheddadi, R., Yu, G., Guiot, J., Harrison, S. P., and Prentice, I. C.: The climate of Europe 6000 years ago, Clim. Dynam., 13, 1-9, doi:10.1007/s003820050148, 1996.

Claussen, M., Kubatzki, C., Brovkin, V., Ganopolski, A., Hoelzmann, P., and Pachur, H.-J.: Simulation of an abrupt change in Saharan vegetation in the Mid-Holocene, Geophys. Res. Lett., 26, 2037-2040, doi:10.1029/1999GL900494, 1999.

Davis, B. and Brewer, S.: Orbital forcing and role of the latitudinal insolation/temperature gradient, Clim. Dynam., 32, 143-165, doi:10.1007/s00382-008-0480-9, 2009.

Davis, B. A. and Stevenson, A. C.: The $8.2 \mathrm{ka}$ event and Early-Mid Holocene forests, fires and flooding in the Central Ebro Desert, NE Spain, Quaternary Sci. Rev., 26, 1695-1712, doi:10.1016/j.quascirev.2007.04.007, 2007.

Davis, B. A. S., Brewer, S., Stevenson, A. C., Guiot, J., and Contributors, D.: The temperature of Europe during the Holocene reconstructed from pollen data, Quaternary Sci. Rev., 22, 17011716, 2003.

Denton, G. H., Alley, R. B., Comer, G. C., and Broecker, W. S.: The role of seasonality in abrupt climate change, Quaternary Sci. Rev., 24, 1159-1182, doi:DOI:10.1016/j.quascirev.2004.12.002, 2005.

Fischer, N. and Jungclaus, J. H.: Effects of orbital forcing on atmosphere and ocean heat transports in Holocene and Eemian climate simulations with a comprehensive Earth system model, Clim. Past, 6, 155-168, doi:10.5194/cp-6-155-2010, 2010.

Gladstone, R. M., Ross, I., Valdes, P. J., Abe-Ouchi, A., Braconnot, P., Brewer, S., Kageyama, M., Kitoh, A., Legrande, A., Marti, O., Ohgaito, R., Otto-Bliesner, B., Peltier, W. R., and Vettoretti, G.: Mid-Holocene NAO: A PMIP2 model intercomparison, Geophys. Res. Lett., 32, L16707, doi:10.1029/2005GL023596, 2005.

Hibler, W.: Dynamic thermodynamic sea ice model, J. Pys.
Oceanogr., 9, 815-846, 1979.

Joussaume, S. and Braconnot, P.: Sensitivity of paleoclimate simulation results to season definitions, J. Geophys. Res., 102, 1943 1956, doi:10.1029/96JD01989, 1997.

Jungclaus, J. H., Keenlyside, N., Botzet, M., Haak, H., Luo, J. J., Latif, M., Marotzke, J., Mikolajewicz, U., and Roeckner, E.: Ocean circulation and tropical variability in the coupled model ECHAM5/MPI-OM, J. Climate, 19, 3952-3972, 2006.

Liu, Z., Wang, Y., Gallimore, R., Notaro, M., and Prentice, I. C.: On the cause of abrupt vegetation collapse in North Africa during the Holocene: Climate variability vs. vegetation feedback, Geophys. Res. Lett., 33, L22709, doi:10.1029/2006GL028062, 2006.

Lorenz, S. J., Kim, J., Rimbu, N., Schneider, R. R., and Lohmann, G.: Orbitally driven insolation forcing on Holocene climate trends: Evidence from alkenone data and climate modeling, Paleoceanography, 21, PA1002, doi:10.1029/2005PA001152, 2006.

Marsland, S. J., Haak, H., Jungclaus, J. H., Latif, M., and Roske, F.: The Max-Planck-Institute global ocean/sea ice model with orthogonal curvilinear coordinates, Ocean Modell., 5, 91-127, 2003.

Milankovic, M.: Kanon der Erdbestrahlung und seine Anwendung auf das Eiszeitenproblem, Special Publication, R. Serb. Acad. Belgrade, 132, 633 pp., 1941.

Nesje, A., Matthews, J. A., Dahl, S. O., Berrisford, M. S., and Andersson, C.: Holocene glacier fluctuations of Flatebreen and winter-precipitation changes in the Jostedalsbreen region, western Norvay, based on glaciolacustrine sediment records, The Holocene, 11, 267-280, available at: http://hol.sagepub.com/ content/11/3/267.abstract, 2001.

Otto, J., Raddatz, T., Claussen, M., Brovkin, V., and Gayler, V.: Separation of atmosphere-ocean-vegetation feedbacks and synergies for mid-Holocene climate, Geophys. Res. Lett., 36, L09701, doi:10.1029/2009GL037482, 2009.

Raddatz, T. J., Reick, C. H., Knorr, W., Kattge, J., Roeckner, E., Schnur, R., Schnitzler, K. G., Wetzel, P., and Jungclaus, J.: Will the tropical land biosphere dominate the climate-carbon cycle feedback during the twenty-first century?, Clim. Dynam., 29, 565-574, 2007.

Raymo, M. E. and Nisancioglu, K.: The 41 kyr world: Milankovitch's other unsolved mystery, Paleoceanography, 18, 1011, doi:10.1029/2002PA000791, 2003.

Renssen, H., Goosse, H., Fichefet, T., Brovkin, V., Driesschaert, E., and Wolk, F.: Simulating the Holocene climate evolution at northern high latitudes using a coupled atmospheresea ice-ocean-vegetation model, Climate Dynamics, 24, 23-43, doi:10.1007/s00382-004-0485-y, 2005.

Renssen, H., Seppa, H., Heiri, O., Roche, D. M., Goosse, H., and Fichefet, T.: The spatial and temporal complexity of the Holocene thermal maximum, Nat. Geosci., 2, 411-414, doi:10.1038/ngeo513, 2009.

Roeckner, E., Bäuml, G., Bonaventura, L., Brokopf, R., Esch, M., Giorgetta, M., Hagemann, S., Kirchner, I., Kornblueh, L., Manzini, E., Rhodin, A., Schlese, U., Schulzweida, U., and Tompkins, A.: The atmospheric general circulation model ECHAM5. Part I: Model description., Tech. Rep. Rep. 349, 127 pp., Max Planck Institute for Meteorology, Available from MPI for Meteorology, Bundesstr. 53, 20146 Hamburg, Germany, 2003.

Semtner, A. J.: Model for thermodynamic growth of sea ice in nu- 
merical investigations of climate, J. Phys. Oceanogr., 6, 379-389, 1976.

Sundqvist, H. S., Zhang, Q., Moberg, A., Holmgren, K., Körnich, H., Nilsson, J., and Brattström, G.: Climate change between the mid and late Holocene in northern high latitudes - Part 1: Survey of temperature and precipitation proxy data, Clim. Past, 6, 591608, doi:10.5194/cp-6-591-2010, 2010.

Tarasov, P. E., Guiot, J., Cheddadi, R., Andreev, A. A., Bezusko, L. G., Blyakharchuk, T. A., Dorofeyuk, N. I., Filimonova, L. V., Volkova, V. S., and Zernitskaya, V. P.: Climate in northern Eurasia 6000 years ago reconstructed from pollen data, Earth Planet. Sci. Lett., 171, 635-645, doi:10.1016/S0012-821X(99)00171-5, 1999.

Vamborg, F. S. E., Brovkin, V., and Claussen, M.: The effect of a dynamic background albedo scheme on Sahel/Sahara precipitation during the mid-Holocene, Clim. Past, 7, 117-131, doi:10.5194/cp-7-117-2011, 2011.
Wanner, H., Beer, J. Bütikofer, J., Crowley, T., Cubasch, U., Flückiger, J., Goosse, H., Grosjean, M., Joos, F., Kaplan, J., Küttel, M., Müller, S., Prentice, I., Solomina, O., Stocker, T., Tarasov, P., Wagner, M., and Widmann, M.: Mid- to Late Holocene climate change: an overview, Quaternary Sci. Rev., 27, 1791-1828, 2008.

Wu, H., Guiot, J., Brewer, S., and Guo, Z.: Climatic changes in Eurasia and Africa at the last glacial maximum and midHolocene: reconstruction from pollen data using inverse vegetation modelling, Clim. Dynam., 29, 211-229, 2007. 